\title{
Prestamista, garante y deudor. El FMI en América Latina y el Caribe en la década posterior a la crisis financiera ${ }^{1}$
}

\author{
Credor, fiador e devedor. O FMI na América Latina e no \\ Caribe na década posterior à crise financeira
}

\section{Creditor, guarantor and debtor. The IMF in Latin America and the Caribbean in the decade after the financial crisis}

\author{
(iD) Pablo Nemiña \\ Investigador Adjunto del Consejo Nacional de Investigaciones Científicas y Técnicas, \\ Buenos Aires, Argentina. \\ pablonemina@yahoo.com.ar \\ (iD) Juan Larralde \\ Analista de Relaciones y Acuerdos Internacionales del Banco Central de la República \\ Argentina, Buenos Aires, Argentina. \\ jlarralde@gmail.com
}

\begin{abstract}
Resumen: Luego de un lustro de repliegue, durante el estallido de la crisis financiera internacional, el G20 posicionó nuevamente al FMI como una institución financiera internacional relevante. Aunque buena parte de sus créditos fueron a Europa, el Fondo también tuvo una presencia activa en América Latina y el Caribe. Apoyado en una metodología cualitativa y cuantitativa, el presente trabajo analiza, desde una perspectiva de economía política, la evolución y las características del vínculo financiero entre el FMI y la región durante el decenio posterior a la crisis financiera global. Se propone que, debido a los cambios en su política crediticia y las diferentes
\end{abstract}

1 Se agradecen los comentarios de Martín Schorr y de Diana Tussie; naturalmente, se los exime de toda responsabilidad en cuanto a los errores u omisiones existentes. 
necesidades de los países de la región, el FMI desempeñó tres roles luego de la crisis: prestamista, garante e, inéditamente, deudor.

Palabras clave: FMI. América Latina y el Caribe. Créditos. Acuerdos. Condicionalidades.

Resumo: Após uma retirada brilhante, durante a eclosão da crise financeira internacional, o G20 colocou novamente o FMI como uma instituição financeira internacional relevante. Embora muitos de seus créditos fossem para a Europa, o Fundo também tinha presença ativa na América Latina e no Caribe. Com base em uma metodologia qualitativa e quantitativa, este trabalho analisa, a partir de uma perspectiva de economia política, a evolução e as características do vínculo financeiro estabelecido entre o FMI e a região durante a década posterior à crise financeira global. Propõe-se que, devido às mudanças em sua política de crédito e às diferentes necessidades dos países da região, o FMI desempenhou três papéis após a crise: credor, garantidor e, sem precedentes, devedor.

Palavras-chave: FMI. América Latina e Caribe. Créditos. Acordos. Condicionalidades.

Abstract: After a brilliant retreat, during the emergence of the global financial crisis, the G20 placed the IMF again as a relevant international financial institution. Although a large part of its credit to Europe, the Fund also had an active presence in Latin America and in the Caribbean. Based on a qualitative and quantitative methodology, this paper analyzes, from a political economy perspective, the evolution and characteristics of the financial bond between the IMF and the region during the decade that followed the financial crisis. It is proposed that due to the changes in its credit policy and the different needs of the countries of the region, the IMF played three different roles after the crisis: creditor, guarantor and, unprecedentedly, debtor.

Keywords: IMF. Latin America and the Caribbean. Credits. Agreements. Conditionalities.

Data de recebimento do artigo: 01/03/2019

Data de aprovação do artigo: 30/04/2019 


\section{Introducción}

Los salvatajes otorgados por el FMI a comienzos del nuevo siglo para financiar las crisis neoliberales en Brasil, Argentina y Uruguay habían Ilevado la deuda de América Latina y el Caribe con el FMI a 47.883 millones de dólares en 2003 , un récord histórico equivalente al $10.5 \%$ de las exportaciones de la región en ese año. ${ }^{2}$ Sólo tres años después la deuda de la región se había desplomado a 744 millones de dólares, un valor exiguo, equivalente a menos del $0.1 \%$ de las exportaciones de ese mismo año, y el menor desde 1971 en términos reales. ${ }^{3}$ La bonanza económica derivada del boom de las materias primas y el interés de los gobiernos progresistas por ganar márgenes de autonomía financiera y política habían permitido cancelar rápidamente la deuda con el FMI. Sin embargo, a cuatro años del estallido de la crisis financiera, los créditos pendientes con el Fondo se habían triplicado (para luego disminuir un poco) y se habían aprobado líneas de crédito precautorias por casi 80.000 millones de dólares. Como el tango de Aníbal Troilo, ${ }^{4}$ aunque parece haberse ido, el FMI siempre está volviendo a América Latina.

Luego del estallido de la crisis financiera internacional, el Fondo volvió al centro de la escena, relegitimado por el G20 como auditor y prestamista (WADE, 2011). A las evaluaciones macroeconómicas anuales de los países miembros realizadas a través de las consultas del Artículo IV, el Fondo incorporó la revisión periódica bilateral del sector financiero de sus miembros (FSAP, por sus siglas en inglés), el análisis del riesgo de contagio en las economías de importancia sistémica (GALLEGO; L'HOTELLERIE-FALLOIS; LÓPEZVICENTE, 2018), y la difusión de estándares y normas de "buenas prácticas" en áreas pertinentes, como la generación y divulgación de estadísticas, la supervisión del sector financiero y la estructura institucional de los mercados (BEST, 2010). Por otra parte, se consolidó como el principal prestamista multilateral al otorgar, des-

\footnotetext{
2 Según datos de CEPALStat.

3 Según datos de CEPALStat y el FMI, respectivamente.

4 Nos referimos a Nocturno a mi barrio, el tango del célebre compositor argentino Aníbal Troilo.
} 
Prestamista, garante y deudor. El FMI en América Latina y el Caribe...

de 2008, créditos por más de 200 mil millones de dólares, lo cual constituyó la mayor marca histórica del organismo de sus créditos como porcentaje del PBI mundial y estuvo muy cerca de alcanzar el pico máximo como porcentaje de las importaciones (REINHART; TREBESCH, 2016, p. 4). En cuanto a la distribución, dos terceras partes constituyeron grandes paquetes de financiamiento a países de la periferia de Europa, entre los que se destacan Grecia, Irlanda, Portugal y Rumania (REINHART; TREBESCH, 2016).

Aunque buena parte del financiamiento del Fondo estuvo centrado en Europa, y eso motivó una multiplicidad de trabajos que analizaron ese vínculo (BLUSTEIN, 2016; JOYCE, 2012), el organismo también tuvo una presencia activa en América Latina y el Caribe, en la cual volvió a celebrar una Asamblea Anual después de 48 años, en octubre de 2015, en Lima, Perú. Acaso por no incluir grandes desembolsos condicionales (lo cual ha cambiado con el reciente programa Stand by con Argentina), la intervención del Fondo en la región durante y luego de la crisis financiera no fue abordada de manera sistemática, y sólo Jiménez y Lorenzo (2010) y Nemiña y Larralde (2018) analizaron aspectos parciales. Si bien el rápido aumento de los precios de los productos primarios luego de la caída de Lehman Brothers moderó el impacto de la crisis en los países exportadores de esos bienes, las naciones de Centroamérica y el Caribe sufrieron en mayor medida debido a que fueron afectadas por la caída de las remesas y del turismo desde Estados Unidos respectivamente. Asimismo, grandes economías como México y Colombia suscribieron significativos programas precautorios para reforzar la confianza de los inversores privados. Por último, el Fondo se mostró activo al otorgar asistencia concesional a países afectados por desastres naturales.

Además de desempeñarse en su tradicional rol de prestamista, el FMI se calzó el traje de deudor de manera inédita en la región, ya que diversos países se sumaron a los acuerdos de financiamiento multilaterales y bilaterales que complementan los recursos que el FMI obtiene por medio de las cuotas. 
Prestamista, garante y deudor. El FMI en América Latina y el Caribe...

El presente trabajo se propone analizar la economía política de la evolución y las características del vínculo financiero entre el FMI y Latinoamérica y el Caribe durante el decenio posterior a la crisis financiera global. Se propone que, debido a las trasformaciones por las que atravesó y las diferentes necesidades de los países de la región, el FMI desempeñó tres roles luego de la crisis: prestamista, garante (mediante el otorgamiento de créditos precautorios) y deudor. El estudio se organiza en tres apartados. En el primero se revisa la intervención del FMI en las crisis financieras sistémicas de la década de 1990; luego, se repasan el repliegue de la institución durante la década de 2000 en razón de la bonanza económica en la periferia, en especial América Latina, y las transformaciones en su esquema de gobernanza. En la tercera sección, dividida en dos subsecciones, se analiza en detalle la intervención del FMI en la región durante el decenio posterior a la crisis financiera global, haciendo hincapié en los roles de prestamista, garante y deudor. Cierra el trabajo un apartado de conclusiones.

\section{¿De dónde venimos? El Fondo frente a las crisis de los ‘90}

Durante la década de 1990 la periferia fortaleció su integración en las redes financieras globales. La globalización financiera y las bajas tasas de interés alentaron una creciente entrada de capitales en los países en desarrollo. La caída de los regímenes socialistas al Este de la "cortina de hierro" y las crisis inflacionarias motorizaron la expansión casi universal de las reformas pro mercado incluidas en el Consenso de Washington (WOODS, 2006).

El FMI tuvo un rol decisivo en dos sentidos: en tanto consultor, potenció la transición al capitalismo en las ex economías soviéticas e impulsó las reformas estructurales en la periferia (en especial en los países de ingreso bajo) a través de sus recomendaciones y condicionalidades (BABB; KENTIKELENIS, 2017). Para esto el organismo incrementó la cantidad y las áreas de incumbencia que 
Prestamista, garante y deudor. El FMI en América Latina y el Caribe...

Pablo Nemiña •Juan Larralde

abarcaba su condicionalidad, lo cual lo llevó a desplegar un menú de reformas diverso que incluyó reestructurar al Estado, privatizar empresas públicas, desregular y flexibilizar mercados, liberalizar el comercio y desregular la cuenta de capital y financiera (BABB; BUIRA, 2005).

La crisis del "tequila" inauguró la ola de crisis sistémicas durante la segunda mitad de los '90 y sentó el primer precedente acerca de la sostenibilidad del crecimiento basado en las reformas de mercado. No obstante, el Tesoro de Estados Unidos organizó la entrega de un paquete de salvataje de USD 50 mil millones que además involucró al resto de países del G7 y a los organismos multilaterales. Desde entonces el FMI asumió el rol de prestamista de última instancia y garante del repago de las deudas externas (UGARTECHE, 2016). Luego del salvataje a México, el FMI intervino en una sucesión de crisis, entre las que se desatacan la del Sudeste Asiático, Rusia, Turquía, Brasil, Argentina y Uruguay.

A la crisis de México siguieron la de Rusia, el Sudeste Asiático y las del Cono Sur, y en cada una se extendían las críticas a los rescates del FMI. Estilizadamente, desde el progresismo se le criticaba la uniformidad de criterio y que los programas de financiamiento constituían un salvataje para los acreedores externos; los sectores conservadores, fortalecidos desde la asunción de Bush (hijo) en 2001, señalaban que mediante sus salvatajes fomentaba el comportamiento crediticio irresponsable y de esa manera contribuía al riesgo moral (BEMBI; NEMIÑA, 2007). La fracasada intervención en la crisis financiera de la Argentina y la mejora de la situación externa dispararon un período de menor protagonismo para el FMI.

\section{El repliegue}

Luego de 2003 los países de América Latina y el Caribe se vieron beneficiados por un período de crecimiento que permitió poner distancia a las políticas y condicionalidades tradicionales del FMI centradas en el ajuste fiscal. El acelerado incremento del pro- 
Prestamista, garante y deudor. El FMI en América Latina y el Caribe...

Pablo Nemiña •Juan Larralde

ducto de las economías asiáticas -liderado por China- incrementó la demanda de materias primas, lo que conllevó una mejora en el promedio de los términos de intercambio para América Latina del $25.2 \%$ entre 2003 y 2008 con relación al promedio de la década de 1990. Esa mejora benefició en particular a los productores de metales y energía, cuyos términos de intercambio casi se duplicaron durante el mismo período. Al mismo tiempo, la decisión de EE.UU de bajar la tasa de interés para atenuar el estallido de la burbuja puntocom generó una coyuntura de alta liquidez global. Finalmente, debe destacarse que entre 2003 y 2008 ingresaron remesas a América Latina por el equivalente al 1.7\% de su PBI, y en América Central ascendieron al 9.2\% de su PBI (KACEF; LOPEZ MONTI, 2010, p. 44).

Bajo estas circunstancias, la mayoría de los países de la región -al igual que otros países en desarrollo- gozaron de inéditos superávits de cuenta corriente y fiscal simultáneos (KACEF; LOPEZ MONTI, 2010). Los saldos externos positivos permitieron gozar de mayor autonomía para administrar el tipo de cambio ${ }^{5}$ y aumentar las reservas internacionales, las cuales funcionaron como un seguro de liquidez ante un potencial desequilibrio financiero. Esta mejor posición externa atrajo mayores inversiones directas y de portafolio, que fortalecieron la balanza de pagos (OCAMPO; BASTIAN; REIS, 2018).

El superávit fiscal volvió innecesaria la asistencia del FMI y permitió cancelar la deuda de manera anticipada en el marco de un proceso más amplio de desendeudamiento, que permitió lograr mayores márgenes de autonomía frente al capital financiero. Siguiendo a Rusia, que a inicios de 2005 canceló créditos pendientes por más de 3 mil millones de dólares, Brasil, Argentina y Uruguay cancelaron el total de su deuda con el FMI mediante el giro de más de 24 mil, 10 mil, y un mil millones de dólares, respectivamente. En consecuencia, un año antes de la caída de Lehman Brothers, la cartera de préstamos total del FMI se redujo a USD 15.5 mil millones, de los cuales el 46\% estaba concentrado en Turquía

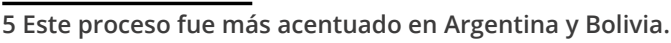


Prestamista, garante y deudor. El FMI en América Latina y el Caribe...

(NEMIÑA; LARRALDE, 2018, p. 300). Asimismo, durante este período los desembolsos del organismo habían caído a mínimos históricos. El desplome de los ingresos derivados de los intereses sobre los créditos desató un inédito déficit operativo en el Fondo, que lo motivó a desprenderse de 1/8 de sus tenencias de oro y a implementar un programa de retiro voluntario para achicar su plantilla de manera significativa (MALKIN; MOMANI, 2011).

Bajo este impulso, liberados de la dependencia recurrente del FMI, los países en desarrollo impulsaron transformaciones en la gobernanza de las Instituciones Financieras Internacionales. En primer lugar, promovieron una reforma en las condicionalidades del FMI, que logró focalizarlas en sus áreas de responsabilidad central, pero no disminuir la cantidad ni eliminar el estigma. En segundo lugar, reclamaron un cambio en la estructura de poder del FMI y del Banco Mundial, con el fin de que la representación de las economías emergentes en estas instituciones reflejara el aumento del peso relativo que habían ganado en la economía internacional (en especial, China) (MOHAN; KAPUR, 2015; RAMOS y otros, 2012). En el caso del FMI, durante el segundo lustro de 2000 se promovieron tres paquetes de reformas de gobierno que procuraron modificar las cuotas y resolver otras debilidades de la organización, como un proceso de elección del director gerente poco meritocrático y la pérdida de relevancia de los votos básicos (LARRALDE, 2015).

La demorada reforma dejó insatisfacción en la periferia, ya que sólo se logró una tibia y demorada redistribución del 6\% de los votos hacia los países en desarrollo (en especial, los BRICS); mientras que Estados Unidos mantiene su poder de veto y el G7, en conjunto, el $41.2 \%$ del total de votos (LARRALDE, 2015). Adicionalmente al aumento y distribución de cuotas, el FMI aumentó los "votos básicos" (votos asignados a cada país independientemente de su aporte de capital/cuota), unificó la fórmula para calcular la cuota, permitió nominar un segundo director ejecutivo alterno para las sillas de más de siete miembros, excluyó el privilegio que poseían los cinco países con cuotas más altas para designar un Director Ejecutivo propio y trasladó dos sillas ocupadas por países euro- 
Prestamista, garante y deudor. El FMI en América Latina y el Caribe...

Pablo Nemiña ·Juan Larralde

peos a favor de los países en desarrollo. Quedaron fuera de la agenda del paquete de reformas la aplicación de "principios de buen gobierno" en el FMI (LARRALDE, 2015).

En lo que respecta a los países de Latinoamérica, las consecuencias de las reformas del gobierno del FMI son dispares. Países como Brasil y México lograron significativos aumentos de cuotas ( $264 \%$ y $245 \%$, respectivamente) e incrementos en su poder de voto dentro del Directorio del FMI ( 0.82 y 0.60 puntos porcentuales). Colombia y Ecuador también alcanzaron aumentos de cuotas por encima de la media (164\% y 131\%), lo que les permitió mejorar levemente su poder de voto (0.07 y 0.02 pp.). Por su parte, las economías más pequeñas de la región tuvieron aumentos de cuota entre el $40 \%$ y $100 \%$, pero lograron mantener su poder de voto en el FMI gracias al incremento de los "votos básicos". Por último, Venezuela y Argentina, con aumentos de cuota muy por debajo de la media ( $40 \%$ y $51 \%$ ), vieron seriamente disminuida su influencia en la toma de decisiones del Directorio del FMI (0.46 y 0.32 pp). 
Prestamista, garante y deudor. El FMI en América Latina y el Caribe...

Pablo Nemiña ·Juan Larralde

Tabla 1 - América Latina y el Caribe. Evolución de los votos y cuota en el FMI pre y post reformas

\begin{tabular}{|c|c|c|c|}
\hline País & $\begin{array}{c}\text { Cuota } \\
\text { (mill DEG) }\end{array}$ & Votos & $\begin{array}{c}\text { Poder } \\
\text { de voto }\end{array}$ \\
\hline Antigua \& Barbuda & 14 & 385 & $0,02 \%$ \\
\hline Argentina & 2.117 & 21.421 & $0,98 \%$ \\
\hline Bahamas & 130 & 1.553 & $0,07 \%$ \\
\hline Barbados & 68 & 925 & $0,04 \%$ \\
\hline Belize & 19 & 438 & $0,02 \%$ \\
\hline Bolivia & 172 & 1.965 & $0,09 \%$ \\
\hline Brazil & 3.036 & 30.611 & $1,40 \%$ \\
\hline Chile & 856 & 8.811 & $0,40 \%$ \\
\hline Colombia & 774 & 7.990 & $0,37 \%$ \\
\hline Costa Rica & 164 & 1.891 & $0,09 \%$ \\
\hline Dominica & 8 & 332 & $0,02 \%$ \\
\hline Dominican Rep & 219 & 2.439 & $0,11 \%$ \\
\hline Ecuador & 302 & 3.273 & $0,15 \%$ \\
\hline El Salvador & 171 & 1.963 & $0,09 \%$ \\
\hline Grenada & 12 & 367 & $0,02 \%$ \\
\hline Guatemala & 210 & 2.352 & $0,11 \%$ \\
\hline Guyana & 91 & 1.159 & $0,05 \%$ \\
\hline Haiti & 82 & 1.069 & $0,05 \%$ \\
\hline Honduras & 130 & 1.545 & $0,07 \%$ \\
\hline Jamaica & 274 & 2.985 & $0,14 \%$ \\
\hline Mexico & 2.586 & 26.108 & $1,20 \%$ \\
\hline Nicaragua & 130 & 1.550 & $0,07 \%$ \\
\hline Panama & 207 & 2.316 & $0,11 \%$ \\
\hline Paraguay & 100 & 1.249 & $0,06 \%$ \\
\hline Peru & 638 & 6.634 & $0,30 \%$ \\
\hline St. Kitts and Nevis & 9 & 339 & $0,02 \%$ \\
\hline St. Lucia & 15 & 403 & $0,02 \%$ \\
\hline Suriname & 92 & 1.171 & $0,05 \%$ \\
\hline Trinidad and Tobago & 336 & 3.606 & $0,17 \%$ \\
\hline Uruguay & 307 & 3.315 & $0,15 \%$ \\
\hline Venezuela & 2.659 & 26.841 & $1,23 \%$ \\
\hline Vincent \& Grenadines & 8 & 333 & $0,02 \%$ \\
\hline Total & 15.934 & 167.339 & $7,67 \%$ \\
\hline
\end{tabular}

\begin{tabular}{|c|c|c|}
\hline \multicolumn{3}{|c|}{ Situación Post Reformas } \\
\hline $\begin{array}{c}\text { Cuota } \\
\text { (mill DEG) }\end{array}$ & Votos & $\begin{array}{l}\text { Poder de } \\
\text { voto }\end{array}$ \\
\hline 20 & 1.684 & $0,03 \%$ \\
\hline 3.187 & 33.357 & $0,66 \%$ \\
\hline 182 & 3.308 & $0,07 \%$ \\
\hline 95 & 2.429 & $0,05 \%$ \\
\hline 27 & 1.751 & $0,03 \%$ \\
\hline 240 & 3.885 & $0,08 \%$ \\
\hline 11.042 & 111.904 & $2,22 \%$ \\
\hline 1.744 & 18.927 & $0,38 \%$ \\
\hline 2.045 & 21.929 & $0,43 \%$ \\
\hline 369 & 5.178 & $0,10 \%$ \\
\hline 12 & 1.599 & $0,03 \%$ \\
\hline 477 & 6.258 & $0,12 \%$ \\
\hline 698 & 8.461 & $0,17 \%$ \\
\hline 287 & 4.356 & $0,09 \%$ \\
\hline 16 & 1.648 & $0,03 \%$ \\
\hline 429 & 5.770 & $0,11 \%$ \\
\hline 182 & 3.302 & $0,07 \%$ \\
\hline 164 & 3.122 & $0,06 \%$ \\
\hline 250 & 3.982 & $0,08 \%$ \\
\hline 383 & 5.313 & $0,11 \%$ \\
\hline 8.913 & 90.611 & $1,80 \%$ \\
\hline 260 & 4.084 & $0,08 \%$ \\
\hline 377 & 5.252 & $0,10 \%$ \\
\hline 201 & 3.498 & $0,07 \%$ \\
\hline 1.335 & 14.829 & $0,29 \%$ \\
\hline 13 & 1.609 & $0,03 \%$ \\
\hline 21 & 1.698 & $0,03 \%$ \\
\hline 129 & 2.773 & $0,05 \%$ \\
\hline 470 & 6.182 & $0,12 \%$ \\
\hline 429 & 5.775 & $0,11 \%$ \\
\hline 3.723 & 38.711 & $0,77 \%$ \\
\hline 12 & 1.601 & $0,03 \%$ \\
\hline 37.730 & 424.801 & $8,42 \%$ \\
\hline
\end{tabular}

\begin{tabular}{|c|c|}
\hline \multicolumn{2}{|c|}{ Variación } \\
\hline $\begin{array}{c}\% \text { Aumento } \\
\text { de cuota }\end{array}$ & $\begin{array}{c}\text { Poder de voto } \\
\text { (ptos porcentuales) }\end{array}$ \\
\hline $48 \%$ & 0,02 \\
\hline $51 \%$ & $-0,32$ \\
\hline $40 \%$ & $-0,01$ \\
\hline $40 \%$ & 0,01 \\
\hline $42 \%$ & 0,01 \\
\hline $40 \%$ & $-0,01$ \\
\hline $264 \%$ & 0,82 \\
\hline $104 \%$ & $-0,03$ \\
\hline $164 \%$ & 0,07 \\
\hline $125 \%$ & 0,02 \\
\hline $40 \%$ & 0,02 \\
\hline $118 \%$ & 0,01 \\
\hline $131 \%$ & 0,02 \\
\hline $68 \%$ & 0,00 \\
\hline $40 \%$ & 0,02 \\
\hline $104 \%$ & 0,01 \\
\hline $100 \%$ & 0,01 \\
\hline $100 \%$ & 0,01 \\
\hline $93 \%$ & 0,01 \\
\hline $40 \%$ & $-0,03$ \\
\hline $245 \%$ & 0,60 \\
\hline $100 \%$ & 0,01 \\
\hline $82 \%$ & 0,00 \\
\hline $102 \%$ & 0,01 \\
\hline $109 \%$ & $-0,01$ \\
\hline $40 \%$ & 0,02 \\
\hline $40 \%$ & 0,02 \\
\hline $40 \%$ & 0,00 \\
\hline $40 \%$ & $-0,04$ \\
\hline $40 \%$ & $-0,04$ \\
\hline $40 \%$ & $-0,46$ \\
\hline $41 \%$ & 0,02 \\
\hline $137 \%$ & 0,75 \\
\hline
\end{tabular}

Fuente: elaboración propia en base a datos del FMI.

Paralelamente, los poderes emergentes propiciaron la creación de nuevas instituciones financieras para disputar la hegemonía de los organismos tradicionales, liderados por EE.UU. y las potencias europeas (CHIN, 2010). Bajo el impulso de los BRICS, se creó el Nuevo Banco de Desarrollo (llamado comúnmente Banco $B R I C S)$ y el Fondo de Reservas de los BRICS, los cuales proveen créditos para el desarrollo y asistencia ante crisis financieras respectivamente. Asimismo, bajo el liderazgo de China se creó el Banco Asiático de Infraestructura e Inversión (BAll), el cual tuvo que sor- 
Prestamista, garante y deudor. El FMI en América Latina y el Caribe...

Pablo Nemiña •Juan Larralde

tear la oposición de EE.UU. y Japón, que resistían la creación de un nuevo competidor para el Banco Mundial y el Banco Asiático de Desarrollo. El BAll aparece como un destacado logro de diplomacia económica del gobierno chino, ya que está integrado por 56 países, entre los que se destacan las potencias europeas (de la región sólo Brasil es miembro fundador, pero varios países, entre ellos la Argentina, han iniciado los trámites de adhesión), y posee un capital autorizado de cien mil millones de dólares que pondrá a disposición para financiar obras de infraestructura que potencien la Iniciativa china del Cinturón y la Ruta de la Seda (CHIN, 2016; VADELL, 2016; WANG, 2017).

Empujados por el ímpetu del momentum poshegemónico (RIGGIROZZI; TUSSIE, 2017), en América Latina también hubo avances, aunque menos notorios que en Asia. En primer lugar, bajo el impulso de Venezuela se creó la Alianza Bolivariana para los Pueblos de Nuestra América (ALBA), que promovió la integración económica, política y social de la región basada en el bienestar social y la asistencia mutua. En el marco del ALBA se creó el Banco del Alba, que ofrece financiamiento para el desarrollo; el SUCRE, una unidad de cuenta que procuró desplazar al dólar como medio de intercambio; y Petrocaribe, una iniciativa de cooperación energética que posibilitó a las naciones caribeñas acceder a petróleo venezolano en condiciones preferenciales. ${ }^{6}$ Esta última tuvo un rol importante al moderar el impacto negativo en los términos de intercambio en las naciones importadoras de energía, en particular centroamericanas y caribeñas. Cuando los precios del barril recuperaron los 100 dólares luego de la crisis financiera, Petrocaribe ofrecía un financiamiento promedio a los miembros equivalente al 2.5\% del PBI (IMF, 2015, p. 36). No obstante, la crisis financiera -luego sociopolítica- desatada en Venezuela por la caída del precio del petróleo erosionó la sostenibilidad de esos procesos. En el Cono Sur, motorizadas por el empuje de la Unasur, las iniciativas más destacadas fueron dos: la formación, en base a Corporación

6 El acuerdo llegó a abarcar a 18 países miembros y ofrecía financiar a 20 años a una tasa del 1\% hasta el 50\% de las importaciones de energía en función del precio del barril. En 2012 Venezuela llegó a proveer el 43\% de la energía que demandaban Centroamérica y el Caribe, que equivalía a unos 200 mil barriles diarios que se comercializaban en Sucres (Acuña, 2014). 
Prestamista, garante y deudor. El FMI en América Latina y el Caribe...

Pablo Nemiña •Juan Larralde

Andina de Fomento, del Banco de Desarrollo de América Latina, que hoy cuenta con más de 35 mil millones de dólares en activos; y la laboriosa creación del Banco del Sur, aunque la demora en su ratificación por parte de los miembros y el giro a la derecha en la región frenó mucho de su ímpetu.

\section{El regreso del FMI tras la crisis financiera global}

La restricción financiera y la contracción del comercio fueron los principales canales a través de los cuales los países en desarrollo sintieron el impacto de la crisis financiera global. En América Latina, la caída del 15\% de las remesas en 2009 afectó en particular a Haití y a las economías centroamericanas (OCAMPO, 2011), mientras que el desplome del 9.5\% del turismo receptivo impactó ese mismo año sobre el Caribe (IMF, 2010, p. 30). Sin embargo, la recomposición de los precios de los productos primarios y la baja de la tasas de interés derivadas de las políticas expansivas de China y las medidas contracíclicas acordadas en las Cumbres del G20 inmediatamente posteriores a la crisis alentaron, respectivamente, una rápida recuperación de las economías del Cono Sur. En cambio, México, América Central y varias naciones del Caribe, cuyas economías estaban estrechamente vinculadas a EE.UU. a través del comercio, los flujos de remesas y el turismo, respectivamente, mostraron una recuperación más lenta y sufrieron mayores tensiones en la balanza de pagos (GRIFFITH-JONES; OCAMPO, 2009; OCAMPO, 2011).

El G20 también impulsó al FMI como el principal instrumento multilateral encargado de promover la estabilidad financiera global, para lo cual se duplicaron sus recursos a más de $660 \mathrm{mil}$ millones de dólares a través del aumento de los créditos bilaterales y la aprobación de la $14^{\mathrm{a}}$ reforma de las cuotas. Asimismo, con el fin de incrementar su capacidad de fuego ante la crisis, se amplió el acuerdo multilateral (NAB, por sus siglas en inglés) y se consolidaron acuerdos bilaterales de financiamiento (BBA) entre el FMI y los 
Prestamista, garante y deudor. El FMI en América Latina y el Caribe...

Pablo Nemiña •Juan Larralde

40 países que proveen recursos adicionales al organismo por 255 mil y 440 mil millones de dólares, respectivamente.

\section{El FMI como deudor}

La creación del acuerdo bilateral y la ampliación del NAB tuvieron una doble motivación. Por un lado, reforzar las líneas de financiamiento del FMI debido a la demora en la aprobación de la reforma de las cuotas por la oposición republicana en el Congreso de los EE.UU.; por otro, brindar mayor margen de participación a los países en desarrollo y las potencias emergentes, en línea con el reclamo de mejorar la representación de estos países en las instituciones de Bretton Woods. En este sentido, aparte de los países del bloque BRICS, vale destacar la participación de cuatro países latinoamericanos en esos fondos adicionales (ver en Tabla 2).

Tabla 2 - Acuerdos multilaterales y bilaterales de financiamiento del FMI. Países miembros y montos comprometidos en millones de USD. Detalle países de América Latina

\begin{tabular}{lccc}
\hline & $\begin{array}{c}\text { General Agreements to } \\
\text { Borrow (GAB) }\end{array}$ & $\begin{array}{c}\text { New Arrangements to } \\
\text { Borrow (NAB) }\end{array}$ & $\begin{array}{c}\text { Bilateral Borrowing } \\
\text { Agreements (BBA) }\end{array}$ \\
\hline Año de creación & 1962 & 1998 & 2012 \\
\hline Alemania & 3.332 & 18.046 & 46.895 \\
Arabia Saudita & 2.100 & 7.914 & 15.000 \\
Argelia & & & 5.000 \\
Australia & & 3.109 & 6.454 \\
Austria & & 2.546 & 6.927 \\
Bélgica & 833 & 5.592 & 11.289 \\
Brasil & & 6.217 & 10.000 \\
Brunei & & & 300 \\
Canadá & 1.250 & 5.423 & 11.480 \\
Chile & & 967 & 960 \\
China & & 22.205 & 43.000
\end{tabular}


Prestamista, garante y deudor. El FMI en América Latina y el Caribe...

Chipre

476

Corea del Sur

4.683

15.000

Dinamarca

2.282

5.989

Eslovaquia

1.763

Eslovenia

1.028

España

4.767

16.792

Estados Unidos

5.950

39.483

Filipinas

476

4.249

Finlandia

1.587

1.000

Francia

2.380

13.271

35.482

Grecia

1.177

Hong Kong

476

India

6.217

10.000

Irlanda

1.341

Israel

476

Italia

1.547

9.658

26.532

Japón

2.975

46.912

60.000

Kuwait

478

Luxemburgo

690

2.328

Malasia

476

1.000

Malta

294

México

Noruega

3.553

10.000

Nueva Zelanda

2.753

8.400

Países Bajos

476

1.000

Perú

1.190

6.433

15.379

Polonia

1.800

1.540

Portugal

1.097

Reino Unido

2.380

13.271

12.850

Rep Checa

1.695

Rusia

6.217

10.000

Singapur

908

4.000

Sudáfrica

476

2.000 
Prestamista, garante y deudor. El FMI en América Latina y el Caribe...

Pablo Nemiña •Juan Larralde

\begin{tabular}{lccc} 
Suecia & 536 & 3.158 & 10.360 \\
Suiza & 1.428 & 7.757 & 8.585 \\
Tailandia & & 476 & 4.000 \\
Turquía & & & 5.000 \\
\hline Total & 25.901 & 255.320 & 440.655 \\
\hline Subtotal países & 0 & 10.737 & 22.500 \\
LATAM & & $4,2 \%$ & $5,1 \%$ \\
\hline $\begin{array}{l}\text { Proporción países } \\
\text { LATAM sobre total }\end{array}$ & &
\end{tabular}

Fuente: elaboración propia en base a datos del FMI.

Brasil, México, Chile y Perú contribuyeron con recursos a los fondos multilaterales y bilaterales de financiamiento adicional del FMI. De esta manera, cuando esos recursos son activados, se produce el hecho inédito de que países de América Latina se convierten en acreedores del FMI. ${ }^{7}$ En 2010, Brasil, conjuntamente con el resto de los países del bloque BRICS, concedió al FMI el equivalente a 10 mil millones de dólares a cambio de la suscripción de un título 8 (luego acordó participar del NAB con más de 6 mil millones de dólares), lo cual lo convirtió en el primer país de la región en ser acreedor del organismo. Luego, México, Chile y Perú pusieron a disposición del FMl 13.5 mil, 1.9 mil y 1.5 mil millones de dólares respectivamente, sumando sus aportes al NAB y al BBA.

De esta manera, a través de los NAB y los acuerdos bilaterales de préstamo, los cuatro países de la región han puesto a disposición del FMI a comienzos de 2019 fondos por más de 23 mil millones de dólares.

El hecho constituye una situación inédita en términos históricos, y de vital importancia para el continuo proceso de reposicionamiento de los países en desarrollo y la región en los organismos multilaterales. No obstante, aún se trata de cifras modestas con relación tanto a la magnitud total de los fondos (los aportes equi-

\footnotetext{
7 En rigor, los países son acreedores de los usuarios de esos recursos por intermedio del FMI. Por otra parte, también vale mencionar que todos los países miembros son acreedores del FMI por el monto equivalente a sus cuotas. No obstante estas precisiones, se trata de una situación excepcional que -aunque moderada e incipiente- marca un contrapunto con más de 70 años de deudas latinoamericanas con el FMI.

8 Los países BRICS completaron su adhesión a través de la compra de notas (títulos) que integran sus reservas (Moreno, 2013).
} 
Prestamista, garante y deudor. El FMI en América Latina y el Caribe...

Pablo Nemiña •Juan Larralde

valen al $4.2 \%$ y el $5.1 \%$ de las líneas de crédito) como de las reservas de esos países (los fondos comprometen menos del 5\% en promedio de las divisas atesoradas ${ }^{9}$ ), y uno de los países -Méxicoha suscripto diversos acuerdos de financiamiento precautorios con el Fondo, lo cual lo ubica como acreedor y potencial deudor de manera simultánea.

Por último, cabe señalar que para la activación de los NAB y los acuerdos bilaterales de préstamos del FMI es necesaria la conformidad previa de los participantes que representen al menos el $85 \%$ del total de acuerdos de crédito. De esta manera, frente a una crisis financiera de significativa magnitud, el poder de fuego del FMI ya no depende de la cooperación económica internacional de los 189 países miembros, sino que está sujeto a la voluntad de un círculo cerrado de 40 países que prestan fondos al FMI a través de estos programas. Entre ellos se destaca la situación de Japón, Estados Unidos y el bloque BRIC, quienes al tener comprometido cada uno más del $15 \%$ del total de los recursos NAB o BBA, poseen un poder de veto para la utilización de estos fondos. Así, la ampliación de la participación de los países en desarrollo ha generado, hasta el momento, una gobernanza alternativa más amplia que la tradicional, pero también elitista y restrictiva.

\section{Prestamista y garante}

Ante el estallido de la crisis financiera, el G20 emplazó al FMI a que contribuyera a morigerar el impacto recesivo en los países que atravesaban crisis de balanza de pagos. Para eso, el Fondo aumentó los niveles de acceso a su financiamiento y facilitó la concentración de desembolsos al inicio de los programas; simplificó su menú de líneas de financiamiento, eliminando aquellas menos utilizadas y lanzó la Línea de Crédito Flexible (LCF), que ofrecía

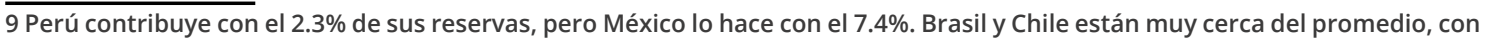
el $4.2 \%$ y el $4.9 \%$ respectivamente. Datos del IRFCL - FMI a finales del primer trimestre de 2019. 
Prestamista, garante y deudor. El FMI en América Latina y el Caribe...

Pablo Nemiña •Juan Larralde

asistencia financiera precautoria e ilimitada y sin condicionalidades, aunque sujeta a una rigurosa evaluación de precalificación.

Con relación a las condicionalidades, el Fondo impulsó una serie de cambios buscando reducir el estigma que acompañaba a sus créditos, entre los cuales se destacan tres: limitó las condiciones tradicionales vis a vis una mayor utilización de medidas de precalificación; discontinuó los llamados performance criteria, condiciones estructurales cuyo incumplimiento motivaba una sanción formal o un waiver por parte del organismo; y restringió la condicionalidad a sus áreas centrales de expertise, esto es, temas monetarios, fiscales, cambiarios y financieros. Sin embargo, no lograron suprimir el sesgo ortodoxo que restringe el espacio para la implementación de políticas contracíclicas en los países deudores (KENTIKELENIS; STUBBS; KING, 2016).

El FMI también buscó cambiar su ropaje ortodoxo y a través de diversas publicaciones procuró matizar su tradicional enfoque neoclásico en la política económica. En ellas destacó el beneficio positivo que trae al crecimiento económico la redistribución del ingreso, ponderó las ventajas del gasto público para restablecer la actividad y de los controles a la cuenta de capital para atenuar la volatilidad cambiaria, e insinuó que el neoliberalismo aumentaba la desigualdad, afectando el crecimiento (OSTRY; LOUNGANI; FURCERI, 2016). Si bien discursivamente se muestra abierto a implementar controles de capital (GRABEL, 2011), en la práctica sólo los acepta en economías extremadamente vulnerables (GALLAGHER; TIAN, 2017). Asimismo, las políticas fiscales expansivas quedan reservadas a los países que disponen de margen presupuestario para hacerlo, lo cual deja afuera a buena parte de los países en desarrollo (BAN; GALLAGHER, 2015). Si bien estas novedades son bienvenidas, parece apresurado proclamar un quiebre en la perspectiva ortodoxa tradicional que ha caracterizado a la institución (VERNENGO; FORD, 2014).

En los años posteriores a la crisis el FMI concentró la mayor parte de su financiamiento en la periferia de Europa, donde el corset que impone el euro limitaba el margen para hacer política mo- 
Prestamista, garante y deudor. El FMI en América Latina y el Caribe...

Pablo Nemiña •Juan Larralde

netaria contracíclica. Así, a fines de 2015 casi el 59\% de la cartera de créditos pendientes de reembolso del organismo -unos USD 47 mil millones de dólares- ${ }^{10}$ estaba concentrada en países integrantes de la Unión Europea. No obstante, el FMI también incrementó su participación en América Latina y el Caribe. La trayectoria del flujo neto de financiamiento muestra tres etapas bien definidas (ver Gráfico 1): de 2008 a 2011, cuando los desembolsos a países del Caribe afectados por la crisis llevan el crédito pendiente de reembolso con la región de USD 804 millones en 2007 a USD 2.582 millones en 2011; de 2012 a 2017, donde la mejora de las condiciones económicas globales permite cambiar el sentido del flujo (a excepción de 2016, debido a un crédito de 352 millones de dólares a Ecuador para afrontar los gastos derivados del terremoto en Manabí); y a partir de 2018, cuando el deterioro de las condiciones económicas globales, en virtud de la guerra comercial entre EE.UU. y China y la suba de la tasa de interés, presionó sobre la balanza de pagos de países con situaciones externas frágiles como Argentina y Ecuador, ${ }^{11}$ que suscribieron programas Stand by por 57 mil y 4 mil millones de dólares respectivamente. Por el tamaño de sus economías, estos desembolsos "quiebran" la serie y emergen como una potencial punta de lanza del regreso del financiamiento y las condicionalidades del FMI al Cono Sur, una subregión que, gracias a la bonanza económica y la decisión política de los gobiernos de la "ola rosa", había desplazado al FMI como prestamista (aunque no como garante o consultor, como demuestran los programas precautorios a México y Colombia, que se desarrollan más adelante).

10 Según datos del FMI, el $86 \%$ de ese financiamiento correspondía a los salvatajes otorgados a Portugal y a Grecia. 11 Debido a que los datos Ilegan al 31/12/18, el programa stand by con Ecuador quedó fuera del análisis. 
Prestamista, garante y deudor. El FMI en América Latina y el Caribe...

Pablo Nemiña ·Juan Larralde

Gráfico 1 - Desembolsos, reembolsos y flujo neto entre el FMI y América Latina y el Caribe. 2007 - 2018. En USD corrientes

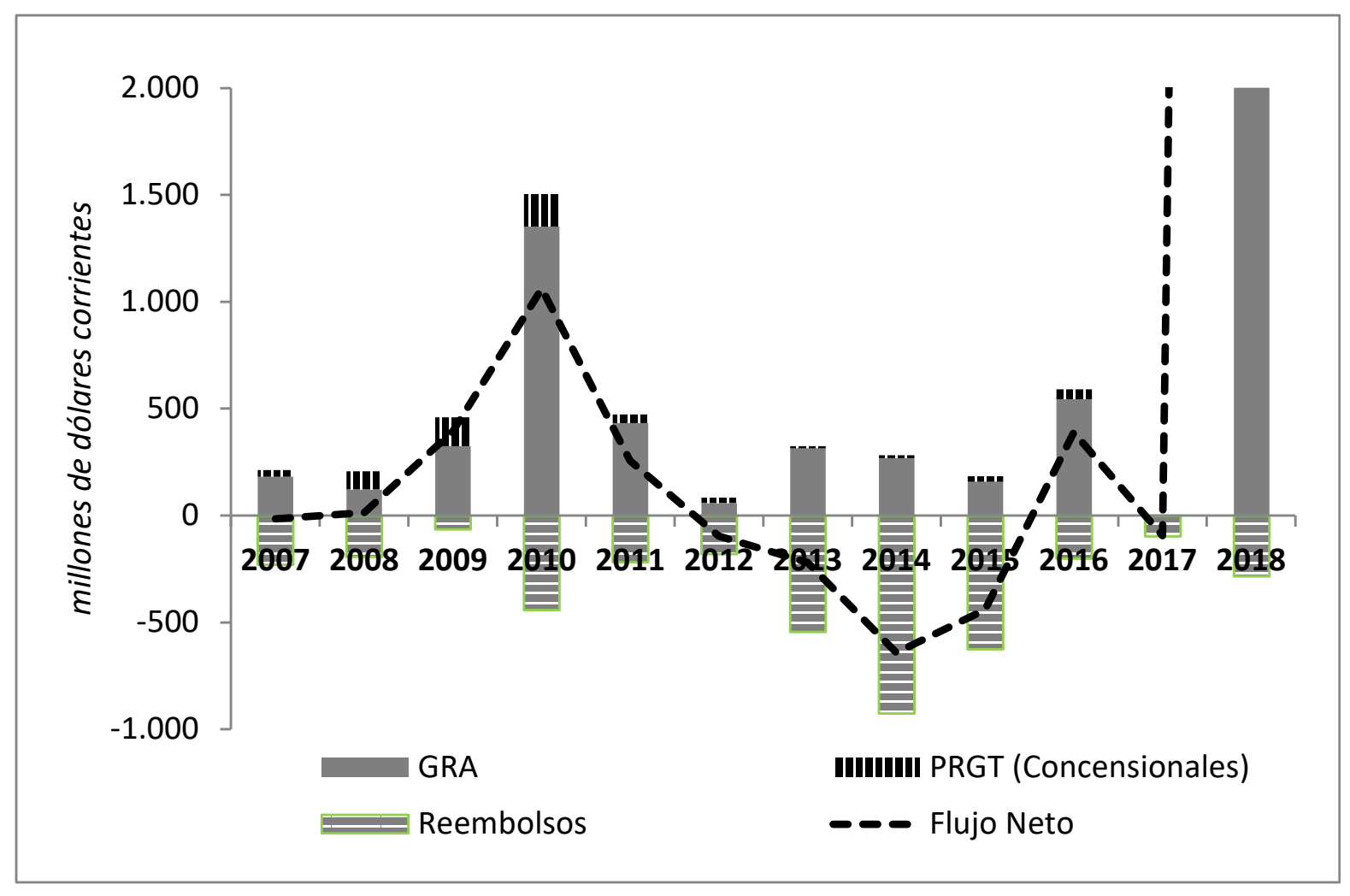

Fuente: elaboración propia en base a datos del FMI.

Las tablas 3, 4 y 5 presentan un detalle de todos los países que acordaron programas de financiamiento y aquellos que efectivamente recibieron desembolsos por parte del organismo. La diferencia radica en que en algunos casos los programas poseen una naturaleza precautoria, es decir, están pensados como una garantía ante los mercados internacionales, concluyen antes del tiempo establecido o debido a una mejora de las condiciones económicas los países deciden no hacer uso de los desembolsos disponibles. 
Prestamista, garante y deudor. El FMI en América Latina y el Caribe...

Pablo Nemiña ·Juan Larralde

Tabla 3 - Detalle de los desembolsos del FMI a países de América Latina y el Caribe entre 2007 y 2018. En USD corrientes

\begin{tabular}{|c|c|c|c|c|c|c|c|c|c|c|c|c|}
\hline \multirow[b]{2}{*}{ País } & \multicolumn{12}{|c|}{ Desembolsos } \\
\hline & 2007 & 2008 & 2009 & 2010 & 2011 & 2012 & 2013 & 2014 & 2015 & 2016 & 2017 & 2018 \\
\hline $\begin{array}{l}\text { Antigua y } \\
\text { Barbuda }\end{array}$ & & & & 31 & 10 & 26 & 36 & & & & & \\
\hline Argentina & & & & & & & & & & & & 28.787 \\
\hline Barbados & & & & & & & & & & & & 50 \\
\hline Belice & & & 7 & & & & & & & & & \\
\hline Dominica & & 3 & 5 & & & 3 & & & 9 & & & \\
\hline Ecuador & & & & & & & & & & 352 & & \\
\hline Granada & & 8 & 12 & 6 & & & & 6 & 6 & 5 & 3 & \\
\hline Haití & 12 & 49 & 62 & 125 & 13 & 23 & 10 & 5 & 10 & 41 & & \\
\hline Jamaica & & & & 785 & 49 & & 272 & 267 & 160 & 114 & & \\
\hline Nicaragua & 19 & 28 & 37 & 20 & 17 & & & & & & & \\
\hline $\begin{array}{l}\text { República } \\
\text { Dominicana }\end{array}$ & 183 & 119 & 314 & 535 & 337 & & & & & & & \\
\hline $\begin{array}{l}\text { San Cristóbal y } \\
\text { Nieves }\end{array}$ & & & 3 & & 34 & 32 & 7 & & & & & \\
\hline Santa Lucía & & & 11 & & 8 & & & & & & & \\
\hline $\begin{array}{l}\text { San Vicente y las } \\
\text { Granadinas }\end{array}$ & & & 6 & & 5 & & & 6 & & & & \\
\hline Surinam & & & & & & & & & & 78 & & \\
\hline $\begin{array}{l}\text { Total } \\
\text { desembolsado }\end{array}$ & 213 & 207 & 459 & 1.503 & 474 & 84 & 325 & 283 & 184 & 591 & 3 & 28.837 \\
\hline
\end{tabular}

Fuente: elaboración propia en base a datos del FMI. Ver Nota. 
Prestamista, garante y deudor. El FMI en América Latina y el Caribe... Pablo Nemiña •Juan Larralde

Tabla 4 - Detalle de los créditos acordados del FMI con países de América Latina y el Caribe entre 2007 y 2018. En USD corrientes. Excluye Acuerdos Precautorios

\begin{tabular}{|c|c|c|c|c|c|c|c|c|c|c|c|c|}
\hline \multirow[b]{2}{*}{ País } & \multicolumn{12}{|c|}{ Monto Acordado (sin acuerdos precautorios) } \\
\hline & 2007 & 2008 & 2009 & 2010 & 2011 & 2012 & 2013 & 2014 & 2015 & 2016 & 2017 & 2018 \\
\hline Antigua and Barbuda & & & & 104 & & & & & & & & \\
\hline Argentina & & & & & & & & & & & & 56.625 \\
\hline Barbados & & & & & & & & & & & & 289 \\
\hline Belice & & & 7 & & & & & & & & & \\
\hline Dominica & & 3 & 4 & & & 3 & & & 9 & & & \\
\hline Dominican Republic & & & 1.718 & & & & & & & & & \\
\hline Ecuador & & & & & & & & & & 352 & & \\
\hline Grenada & & & & 14 & & & & 20 & & & & \\
\hline Haíti & & & & 63 & & & & & 69 & 41 & & \\
\hline Jamaica & & & & 1.264 & & & 948 & & & & & \\
\hline Nicaragua & 123 & & & & & & & & & & & \\
\hline St. Kitts and Nevis & & & 3 & & 81 & & & & & & & \\
\hline St. Lucia & & & 11 & & 8 & & & & & & & \\
\hline St. Vincent and the Grenadines & & & 6 & & 5 & & & 6 & & & & \\
\hline Suriname & & & & & & & & & & 460 & & \\
\hline Total general & 123 & 3 & 1.750 & 1.444 & 94 & 3 & 948 & 26 & 78 & 853 & - & 56.914 \\
\hline
\end{tabular}

Fuente: elaboración propia en base a datos del FMI. Ver Nota.

Tabla 5 - Detalle de los créditos precautorios acordados entre el FMI y países de América Latina y el Caribe entre 2007 y 2018. En USD corrientes

\begin{tabular}{|c|c|c|c|c|c|c|c|c|c|c|c|c|}
\hline \multirow[b]{2}{*}{ País } & \multicolumn{12}{|c|}{ Monto Acordado Precautorios } \\
\hline & 2007 & 2008 & 2.009 & 2.010 & 2.011 & 2.012 & 2.013 & 2.014 & 2.015 & 2.016 & 2.017 & 2.018 \\
\hline Colombia & & & 10.937 & 3.576 & 5.960 & & 5.960 & & 5.457 & 10.997 & & 10.915 \\
\hline Costa Rica & & & 773 & & & & & & & & & \\
\hline Guatemala & & & 990 & & & & & & & & & \\
\hline Honduras & & 60 & & 199 & & & & 188 & & & & \\
\hline Jamaica & & & & & & & & & & 1.607 & & \\
\hline Mexico & & & 49.499 & 48.553 & 72.830 & 72.830 & & 68.573 & & 83.871 & 76.157 & \\
\hline Perú & 272 & & & & & & & & & & & \\
\hline Salvador & & & 807 & 791 & & & & & & & & \\
\hline Total general & 272 & 60 & 63.005 & 53.120 & 78.789 & 72.830 & 5.960 & 68.761 & 5.457 & 96.475 & 76.157 & 10.915 \\
\hline
\end{tabular}

Nota: la reconstrucción de las series estadísticas se hizo en base a la información contenida en dos bases de datos (History of Lending Arrangements y Transactions with the Fund), más la complementación con información recogida manualmente del sitio web del FMI relativa a financiamiento de emergencia.

Fuente: elaboración propia en base a datos del FMI.

Como puede apreciarse, el Caribe constituye la subregión con más países (diez) que recibieron desembolsos del FMl en el decenio posterior a la crisis financiera. Se trata de países en su mayoría altamente endeudados, que sufrieron el impacto externo por la combinación del desplome del turismo receptivo, la suba de los costos financieros y diversos desastres naturales. Muchos de ellos también poseen regímenes cambiarios de paridad fija tipo peg, que impiden amortiguar el shock externo mediante una va- 
Prestamista, garante y deudor. El FMI en América Latina y el Caribe...

Pablo Nemiña •Juan Larralde

riación del tipo de cambio. De los diez países que recibieron financiamiento, cinco fueron programas del tramo superior de crédito ${ }^{12}$ (República Dominicana, Jamaica, Antigua y Barbuda, San Cristóbal y Nieves y Barbados), un programa precautorio (Jamaica) y el resto programas concesionales o de emergencia ante catástrofes naturales como huracanes o terremotos (Dominica, Santa Lucía, San Vicente y las Granadinas, Haití y Granada). A excepción de República Dominicana, que en 2012 decidió discontinuar con el stand by acordado en 2009 debido la exigencia de incrementar las tarifas del servicio de electricidad (JIMÉNEZ, 2012), ${ }^{13}$ los acuerdos restantes de tramo superior apoyaron programas de reestructuración de la deuda (ACEVEDO MEJÍA, 2014); notablemente, se trata de los cuatro países del Caribe más endeudados a 2009 (Gráfico 2). ${ }^{14}$ En estos casos, el FMI actuó no solo como prestamista en economías pequeñas con problemas de balanza de pagos sino, al igual que en Grecia e Islandia pos 2008, como garante de los procesos de reestructuración de deuda.

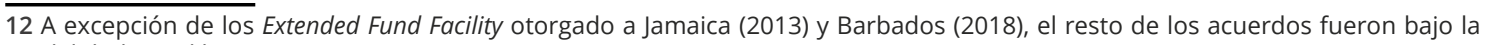
modalidad stand by.

13 En el año 2009, República Dominicana acordó un stand by por 1.718 millones de dólares, de los cuales se desembolsaron 1.186 millones entre los años 2009 y 2011 (ver Tablas 3 y 4), los restantes 532 millones de dólares no se desembolsaron debido a la negativa de aumentar las tarifas eléctricas (Jiménez, 2012).

14 Granada y Belice también pasaron por reestructuraciones durante el período, pero se resolvieron a través de cláusulas de acción colectiva o negociaciones bilaterales. 
Prestamista, garante y deudor. El FMI en América Latina y el Caribe...

Pablo Nemiña •Juan Larralde

\section{Gráfico 2 - Caribe. Deuda pública sobre PBI a fin de 2009}

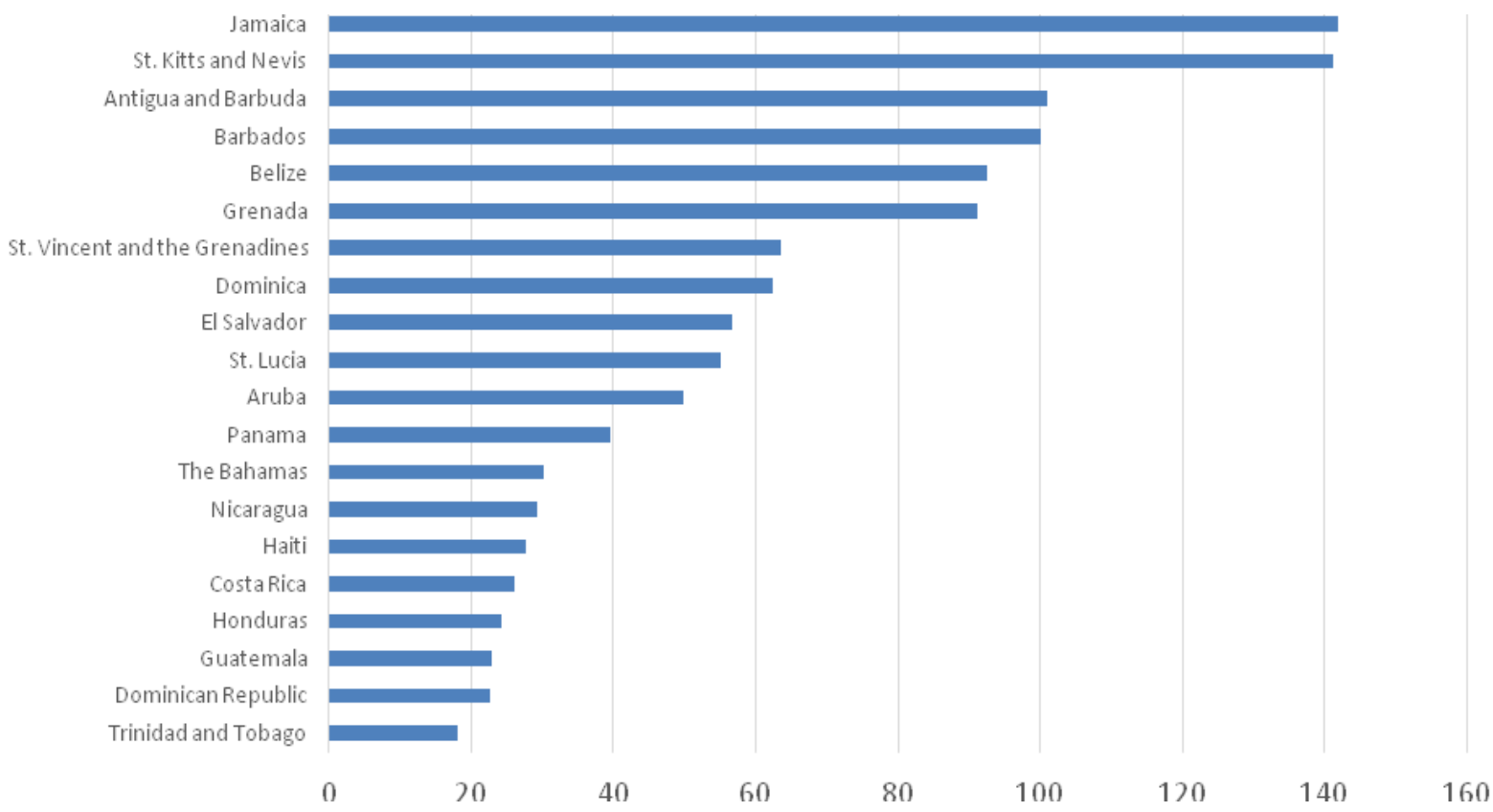

Fuente: elaboración propia en base a datos del WEO, FMI.

Al tratarse de economías pequeñas, los desembolsos tuvieron una escala muy pequeña (el acuerdo más importante, con República Dominicana, no superó los 2 mil millones de dólares). En efecto, durante el período 2008-2015 el desembolso promedio anual del FMI a Latinoamérica fue de 363 millones de dólares, lo cual constituye la etapa con los desembolsos más bajos en términos reales de la historia (NEMIÑA; LARRALDE, 2018, p. 295).

Sin embargo, la situación es completamente diferente cuando se consideran los compromisos de financiamiento, lo cual permite explicar la notoria diferencia entre los créditos acordados y los desembolsos efectivos (ver Tabla 6). Esa diferencia se explica en especial por las Líneas de Crédito Flexibles acordadas anual y, desde 2012, bianualmente con México y Colombia (las últimas por 76 mil y 11 mil millones de dólares, respectivamente), las cuales constituyen programas precautorios que operan como respaldo ante los inversores privados internacionales y que equivalen a no menos del $86 \%$ del total de créditos comprometidos por el organismo para la región durante el período. Como un dato significa- 
Prestamista, garante y deudor. El FMI en América Latina y el Caribe...

Pablo Nemiña •Juan Larralde

tivo, se trata de dos naciones económica y políticamente muy vinculadas con los EE.UU. Aparte de que ambas poseen un acuerdo de libre comercio con la potencia del Norte, México es el segundo destino de las exportaciones norteamericanas (sólo superado por Canadá) y desde hace más de una década EE.UU. ofrece activa colaboración militar en el marco del Plan Colombia. Más recientemente, Colombia emergió como el aliado más cercano de EE.UU. en la posición confrontativa que Washington ha desplegado sobre Venezuela. Un desequilibrio financiero en uno de estos dos países podría traer una desestabilización sobre socios económicos y políticos estrechos de los Estados Unidos.

Tabla 6 - FMI. Desembolsos, créditos acordados y detalle de créditos precautorios en América Latina y el Caribe. En USD corrientes. 2007-2018

\begin{tabular}{|c|c|c|c|c|c|c|c|}
\hline \multirow{2}{*}{ Año } & \multicolumn{4}{|c|}{$\begin{array}{l}\text { Monto Acordado } \\
\text { de los cuales: }\end{array}$} & \multicolumn{3}{|c|}{$\begin{array}{c}\text { Monto Precauorio Vigente } \\
\text { de los cuales: }\end{array}$} \\
\hline & Total & $\begin{array}{l}\text { Tramo } \\
\text { Superior }\end{array}$ & Emergencia & Precautorio & Total & $F C L$ & $S B A$ \\
\hline 2007 & 396 & 123 & & 272 & 272 & & 272 \\
\hline 2008 & 63 & & 3 & 60 & 325 & & 325 \\
\hline 2009 & 64.756 & 1.718 & 32 & 63.005 & 63.337 & 60.436 & 2.901 \\
\hline 2010 & 54.564 & 1.444 & & 53.120 & 55.641 & 52.129 & 3.512 \\
\hline 2011 & 78.884 & 81 & 13 & 78.789 & 79.780 & 78.789 & 991 \\
\hline 2012 & 72.833 & & 3 & 72.830 & 79.780 & 78.789 & 991 \\
\hline 2013 & 6.907 & 948 & & 5.960 & 79.581 & 78.789 & 791 \\
\hline 2014 & 68.788 & 20 & 6 & 68.761 & 74.373 & 74.185 & 188 \\
\hline 2015 & 5.535 & 69 & 9 & 5.457 & 72.323 & 72.140 & 183 \\
\hline 2016 & 97.327 & & 853 & 96.475 & 96.649 & 94.868 & 1.781 \\
\hline 2017 & 76.157 & & & 76.157 & 88.967 & 87.154 & 1.813 \\
\hline 2018 & 67.829 & 56.914 & & 10.915 & 86.951 & 85.289 & 1.662 \\
\hline
\end{tabular}

Fuente: elaboración propia en base a datos del FMI.

En el caso de los países de la región que no cumplían las condiciones ex ante para acceder a la LCF, el Fondo otorgó programas Stand by precautorios en los años inmediatamente posteriores al estallido de la crisis, especialmente en los países de Centroamérica: Costa Rica, El Salvador, Honduras y Guatemala, además de un programa con Jamaica en 2016 y con Perú previo a la crisis. Las 
Prestamista, garante y deudor. El FMI en América Latina y el Caribe...

Pablo Nemiña •Juan Larralde

naciones centroamericanas se vieron afectadas por la caída de la actividad en los EE.UU., especialmente por el canal comercial y financiero: mientras que en promedio el $60 \%$ de las exportaciones de América Central se orientan a EE.UU. debido a la maquila, en los años previos a la crisis recibían el $80 \%$ del flujo de remesas desde aquel país. Las remesas poseen una importancia decisiva en esas economías, con un peso del $10 \%$ del PBI en promedio (Swiston, 2010, p. 11). El Stand by precautorio acordado con Jamaica en 2016 preveía la continuidad del monitoreo del FMI de las metas establecidas en el programa extended fund facility, firmado en 2013; sin embargo, en 2018 las autoridades jamaiquinas discontinuaron el programa del FMI en razón de diferencias en cuanto a las metas fiscales a cumplir (NATIONWIDE NEWSNET, 2018; THE GLANER, 2018).

En este punto también se observa el quiebre que supone el comportamiento financiero del FMI en 2018, ya que debido a la concentración de programas LCF en 2016 y el adelantamiento del financiamiento Stand by a Argentina, la proporción de créditos LCF sobre el total de créditos aprobados se desploma al 16\% (Tabla 6).

El Cuadro 1 resume el análisis al detallar a los países de América Latina y el Caribe que suscribieron programas con el FMI y recibieron financiamiento entre 2007 y 2018. En las primeras dos columnas se indican aquellos países que recibieron desembolsos en el marco de un programa de tipo Stand by de tramo superior (primera columna) o un programa concesional y/o asistencia de emergencia ante catástrofes naturales como huracanes o terremotos (segunda columna). En la tercera, aparecen aquellos países que suscribieron acuerdos precautorios, es decir, que no recibieron desembolsos efectivos (tercera columna). 
Prestamista, garante y deudor. El FMI en América Latina y el Caribe...

Pablo Nemiña •Juan Larralde

Cuadro 1 - Detalle de programas y créditos del FMI con América Latina y el Caribe entre 2007 y 2018

\begin{tabular}{|c|c|c|c|}
\hline & \multicolumn{2}{|c|}{ Acuerdos con desembolsos } & \multirow[t]{2}{*}{ Acuerdos precautorios } \\
\hline & Tramo Superior & $\begin{array}{l}\text { Emergencia y } \\
\text { concesionales }\end{array}$ & \\
\hline Caribe & $\begin{array}{l}\text { Rep. Dominicana } \\
\text { (2009) } \\
\text { Jamaica }(2010,2013) \\
\text { Antigua y Barbuda } \\
\text { (2010) } \\
\text { San Cristóbal y Nieves } \\
\text { (2011) } \\
\text { Barbados (2018) }\end{array}$ & $\begin{array}{l}\text { Dominica }(2008,2009, \\
\quad 2011,2015) \\
\text { Santa Lucía }(2009,2011) \\
\text { San Vicente y las } \\
\text { Granadinas }(2009,2011, \\
2014) \\
\text { Haití }(2010,2015,2016) \\
\text { Granada }(2010,2014)\end{array}$ & Jamaica (2016) \\
\hline $\begin{array}{l}\text { América } \\
\text { Central }\end{array}$ & & $\begin{array}{l}\text { Nicaragua (2007) } \\
\text { Belice (2009) }\end{array}$ & $\begin{array}{l}\text { Perú (2007) } \\
\text { Honduras }(2008,2010, \\
2014) \\
\text { Costa Rica (2009) } \\
\text { Guatemala (2009) } \\
\text { El Salvador (2009, } \\
2010)\end{array}$ \\
\hline $\begin{array}{l}\text { América del Sur } \\
\text { y del Norte }\end{array}$ & $\begin{array}{l}\text { Surinam (2016) } \\
\text { Argentina (2018) }\end{array}$ & Ecuador (2016) & $\begin{array}{l}\text { México (2009 y ss) } \\
\text { Colombia (2009 y ss) }\end{array}$ \\
\hline
\end{tabular}

Nota: San Cristóbal y Nieves también recibió financiamiento de emergencia en 2009. Entre paréntesis se indica el año de suscripción del programa / crédito.

Fuente: elaboración propia en base a datos del FMI.

Como fue señalado, la mayor cantidad de acuerdos se concentró en el Caribe, donde el FMI actuó principalmente como prestamista ante el deterioro de la balanza de pagos debido al impacto de la crisis financiera, la caída del turismo y diversos desastres naturales. En el caso de los países con acuerdos de tramo superior, los acuerdos también sirvieron de garantía ante los acreedores frente a procesos de reestructuración de deuda (excepto Rep. Dominicana). Acaso debido a tratarse de economías más grandes que las caribeñas y la recuperación de la economía estadounidense, la intervención del Fondo en Centroamérica fue esencialmente como garante a través del otorgamiento de acuerdos precautorios en el cenit de la crisis, además de algunos desembolsos concesionales. 
Prestamista, garante y deudor. El FMI en América Latina y el Caribe...

Pablo Nemiña •Juan Larralde

Por último, Colombia, México y Argentina son ejemplos paradigmáticos de su intervención como garante y prestamista. Mientras que a través de los sucesivos programas LCF el Fondo otorgó un importante apoyo financiero y político en países que en la crisis tuvieron dificultades en acceder a los mercados internacionales de capital, el paquete de salvataje a Argentina refleja el regreso del FMI ${ }^{15}$ como prestamista a la región con mayor tasa de suscripción de acuerdos en el mundo (HUTCHISON; NOY, 2003). Y lo hace mediante un programa stand by tradicional con el país que mayor tasa de participación en los programas del Fondo posee en América Latina (REINHART; TREBESCH, 2016: 15).

\section{Reflexiones finales}

Si bien buena parte de su actividad se concentró en Europa, el análisis precedente pone de manifiesto que el FMI estuvo lejos de estar ausente de América Latina y el Caribe durante la década posterior a la crisis financiera. La intervención del Fondo en la región durante ese período estuvo orientada por tres roles: a los tradicionales, de prestamista y garante (este último desde la década de 1980), se agrega la situación novedosa de ser deudor de cuatro países de la región. Comencemos por esto último. La necesidad de incrementar los recursos para afrontar el ahogo financiero de los países afectados por la crisis y la demanda de los países en desarrollo por aumentar su poder en la gobernanza financiera global, confluyeron en el hecho inédito de que Brasil, México, Chile y Perú sean, hoy, prestamistas del FMI. Se trata de un aporte limitado en términos relativos y las proyecciones para estas economías no hacen prever un dinamismo exagerado. No obstante, se trata de una situación destacable por lo inédito en términos históricos y las implicancias políticas sobre el vínculo. Por otra parte, a pesar del

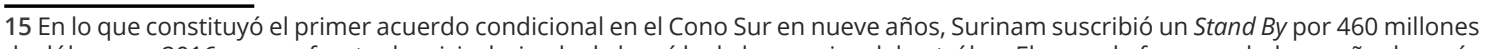
de dólares en 2016 para enfrentar la crisis derivada de la caída de los precios del petróleo. El acuerdo fue cancelado un año después por la negativa del gobierno a implementar las medidas de ajuste requeridas (Bretton Woods Project, 2017). 
Prestamista, garante y deudor. El FMI en América Latina y el Caribe...

antecedente que significó la reestructuración de deuda argentina sin la tutela del organismo, las reestructuraciones de países del Caribe posteriores a la crisis muestran un regreso del Fondo como garante de esos procesos a través de sus créditos, $y$, esencialmente, de sus condicionalidades con sesgo ortodoxo y favorables a los acreedores. Al respecto, el acuerdo de 2013 con Jamaica incluyó una meta de superávit primario del 7,5\% del PBI; así, la isla caribeña logró reducir su endeudamiento gracias a una quita en la deuda, pero también a un profundo ahorro fiscal para hacer frente a los pagos de deuda (CLARKE, 2019).

Con relación a su rol de prestamista, hasta 2017 se observan tres características. Primero, su estrategia financiera se caracterizó principalmente por la aprobación de créditos precautorios a países cuyo ciclo económico posee un vínculo muy estrecho con el de los EE.UU. y, por ende, sufrieron un impacto mayor en términos relativos de la crisis subprime. En este grupo cabe distinguir entre México y Colombia, a quienes otorgó cuantiosos programas precautorios bajo la Línea de Crédito Flexible, y Centroamérica, donde aprobó acuerdos Stand by sin desembolsos. Segundo, el Fondo limitó sus desembolsos a países de ingreso bajo concentrados mayoritariamente en el Caribe, con limitado acceso a financiamiento en los mercados de capital. Aquí pueden identificarse dos grupos, aquellos que suscribieron programas de tramo superior para acompañar procesos de reestructuración de deudas y las islas más pequeñas, que recibieron pequeños desembolsos concesionales o de emergencia ante desastres naturales. Por cierto, esta última se trata de un mecanismo de financiamiento reciente que le permite al Fondo involucrarse en la ventana de ayuda humanitaria. Tercero, el restablecimiento del acceso a los mercados internacionales de crédito, la política preventiva de acumulación de reservas y la asistencia financiera de China (LEITERITZ; CORAL, 2017) permitieron evitar la asistencia del organismo en América del Sur (excepto un crédito para desastres naturales en Ecuador y un acuerdo en Surinam) (STANLEY; FERNÁNDEZ ALONSO, 2016). Sin embargo, la incapacidad de consolidar una red de asistencia 
Prestamista, garante y deudor. El FMI en América Latina y el Caribe...

Pablo Nemiña •Juan Larralde

financiera regional robusta, la caída de los precios de las materias primas y la incertidumbre sobre la continuidad de la liquidez global auguraban condiciones que favorecían el retorno de los créditos del FMI al Cono Sur.

El acuerdo Stand by con Argentina, firmado en 2018 por 57 mil millones, el programa concesional más alto de la historia, de los cuales el organismo adelantó el $75 \%$ del monto disponible para evitar la profundización del deterioro de la economía en el año en que el gobierno de centroderecha y aliado "antipopulista" de EE.UU en la región busca la reelección, seguido por el reciente acuerdo con el gobierno promercado de Moreno en Ecuador, constituye un quiebre en el período y abre la puerta a una profundización del rol de prestamista con el consecuente desafío para la autonomía financiera regional.

Es esperable que una mayor intervención del FMI en América Latina refuerce el giro a la derecha que se abrió con la progresiva retracción de la "ola rosa". Con contadas excepciones, la región se ha acercado ideológicamente al organismo al expandirse las políticas pro mercado que proclaman a la inversión extranjera como motor privilegiado del crecimiento. Un incremento del financiamiento a la región conllevaría un mayor condicionamiento de las políticas económicas regionales hacia la ortodoxia, con el consiguiente aumento de la desigualdad de ingresos y la profundización de la retracción del sector manufacturero.

\section{Referencias}

ACEVEDO MEJIA, Sebastián. Debt, growth and natural disasters: a

Caribbean trilogy. IMF Working Paper, v. 14, n. 125, 2014.

aCuña, Rodrigo. Petrocaribe: a project for development in the

Caribbean and Central America? In: ANGOSto-fernandeZ, Luis (Ed.).

Democracy, revolution and geopolitics in Latin America: Venezuela and

the International Politics of Discontent. New York: Routledge, 2014. 
Prestamista, garante y deudor. El FMI en América Latina y el Caribe...

Pablo Nemiña •Juan Larralde

BABB, Sarah; BUIRA, Ariel. Mission creep, mission push, and discretion: the case of IMF conditionality. In: BUIRA, Ariel. (Ed.). The IMF and the World Bank at Sixty. London, UK: AnthemPress, 2005.

BABB, Sarah; KENTIKELENIS, AleXander. International financial institutions as agents of neoliberalism. En: CAHILL, D. y otros (Eds.). The SAGE handbook of neoliberalism. Thousand OAKs: SAGE Publications, 2017. BAN, Cornel; GALLAGHER, KeVIn. Recalibrating policy orthodoxy: the IMF sinCe the GREAT ReCession. Governance, v. 28, n. 2, P. 131-146, 2015. BeMBi, Mariela; Nemiña, Pablo. Neoliberalismo y desendeudamiento: la relación Argentina - FMI. Buenos Aires: Capital Intelectual, 2007.

BeSt, Jacqueline. Bringing Power Back in: The IMF's constructivist strategy in CRItICAL PERSPeCtive. In: ABDELAL, Rawl; BLYTH, Mark; PARSONS, Craig (Eds.). Constructing the international economy. Ithaca: Cornell UNIVERSITY PRESS, 2010.

BLUSTEIN, PAUL. LaId LOW: INSIDE THE CRISIS that OVERWHELMEd EUROPE AND THE IMF. CANADÁ: CIGI, 2016.

BRETTON WOODS PROJECT. SURINAME WALKS AWAY FROM IMF CONDITIONALITIES, JULY 3, 2017. DISPONIBLE EN: HTTPS://WWW.BRETTONWOODSPROJECT. ORG/2017/07/SURINAME-WALKS-AWAY-IMF-CONDITIONALITIES/. CONSULTADO EL: 8 JUN. 2019.

CHIN, Gregory T. Remaking the ARCHIteCture: the emerging POWERS, SELF-INSuring and regional insulation. International Affairs, v. 86, N. 3, P. 693715, 2010.

CHIN, Gregory T. Asian Infrastructure InVEstment Bank: governance InNoVATION AND prospects. Global governance, v. 22, n. 1, P. 11-25, 2016.

CLARKE, Nigel. LeSSONS FROM JAMAICA FOR SMALL COUNTRIES WITH BIG DEBTS. Financial Times, London, 19 feb. 2019. Disponible EN: hTtPS://WWW. Ft.com/content/04870fa8-2e12-11e9-80d2-7b637a9e1ba1. Consultado EL: 19 FEB. 2019. 
Prestamista, garante y deudor. El FMI en América Latina y el Caribe...

Pablo Nemiña •Juan Larralde

GALLAGHER, Kevin; TIAN, Yuan. Regulating capital flows in emerging markets: The IMF and the global financial crisis. Review of Development FinANCE, v. 7, N. 2, P. 95-106, 2017.

GALLEGO, SONSOLES; L'HOTELLERIE-FALLOIS, PILAR; LÓPEZ-VICENTE, Fernando. El Fondo Monetario Internacional y su papel como Garante de la estabilidad financiera global. Boletín Económico, Banco de España, n. 4, 2018.

GRABEL, ILENE. Not YOUR GRANDFATHeR'S IMF: GLOBAL CRISIS, 'PRODUCtive incoherence' and deVelopmental policy space. Cambridge Journal of Economics, v. 35, N. 5, P. 805-830, 2011.

GRIFFITH-JONES, Stephany; OCAMPO, Juan. A. The FInANCIAL CRISIS AND its impact on developing countries. Working Paper, International Policy Centre for Inclusive Growth, N. 53, 2009.

HUTCHISON, Michael; NOY, Ilan. Macroeconomic effects of IMFSPONSORED PROGRAMS IN LATIN AMERICA: OUTPUT COSTS, PROGRAM RECIDIVISM AND the Vicious CyCle of failed stabilizations. Journal of International Money and Finance, v. 22, N. 7, P. 991-1014, 2003.

IMF. Regional Economic Outlook. Washington: IMF, April 2015. IMF. Regional Economic Outlook. Washington: IMF, May 2010. JiméneZ, Juan Pablo; LOREnZO, Fernando. Los cambios en el FMI y el impacto en su relación con los países de América latina. Pensamiento LATINOAMERICANO, N. 6, P. 255-283, 2010.

JimeneZ, Manuel. Dominican Republic says no plans to renew IMF loan Program. Reuters, 14 feb. 2012. Disponible en: htTPS://LtA.REUters.COM/ aRTICULO/IDLTAL2E8DEF4Q20120214. Consultado el 14 Feb. 2019. JOYCE, Joseph. The IMF and global financial CRISEs: Phoenix RISING? Cambridge: Cambridge University Press, 2012. 
Prestamista, garante y deudor. El FMI en América Latina y el Caribe...

Pablo Nemiña •Juan Larralde

KACEF, Osvaldo; LOPEZ-MONTI, Rafael M. América Latina, del auge a la CRisis: desafíos de política macroeconómica. Revista de la Cepal, N. 100, P. 41-68, 2010.

KENTIKELENIS, AleXAnder; STUBBS, Thomas; KING, LaURence. IMF CONDITIONALITY AND DEVELOPMENT POLICY SPACE, 1985-2014. REVIEW OF International Political Economy, v. 23, n. 4, 2016.

LARRALDE, Juan. Concentración de poder en el gobierno del FMI. Análisis de LAS REFORMAS DE 2006, 2008 y 2010, y su IMPACto sobre LA ARgentinA. Revista CICLOS, A. XXVI, v. XXII, N. 44-45, P. 89-111, 2015.

LEITERITZ, Ralf; CORAL, Horacio. China como fuente de Recursos finanCIEROS y de COOPERACIÓN PARA AmÉRICA Latina y el CARIBE: anÁlisis COMPARAtivo con África. In: PASTRANA, EduARdo; GEHRING, Hubert (Eds.). LA proyección de China en América latina y el Caribe. Bogotá: Editorial PontifiCIA Universidad JaVeriana, 2017.

MALKIN, Anton; MOMANI, Bessma. Emerging POWERS ANd IMF REFORM: WHeRe MUltipolarity in the WORLD eCONOMy is Leading the fund. St Antony's InTERnAtional ReVIEW, v. 7, N. 1, P. 61-78, 2011.

MOHAN, Rakesh; KAPUR, Muneesh. Emerging powers and global goVernance: Whither the IMF? IMF Working Paper, International Monetary Fund, N. 15-219, 2015.

MORENO, Pablo. The metamorphosis of the IMF (2009-2011). Estudios económicos, BANCO de ESPAÑA, N. 78, 2013.

NATIONWIDE NEWSNET. 'JAMAICA MUST NEVER RETURN TO IMF FOR SURVIVAL', says Clarke. Nationwide Newsnet, 12 abr. 2018. Disponible en: http:// NATIONWIDERADIOJM.COM/JAMAICA-MUST-NEVER-RETURN-TO-IMF-FOR-SURVIVAL-SAYSclarke/. Consultado el 14 feb. 2019.

NEMIÑA, PABLO; LARRALDE, JUAN. ETAPAS hISTÓRICAS dE LA RELACIÓN ENTRE el Fondo Monetario Internacional y América Latina (1944-2015). América 
Prestamista, garante y deudor. El FMI en América Latina y el Caribe...

Pablo Nemiña •Juan Larralde

Latina en la Historia Económica, v. 25, N. 1, P. 275-313, enero-Abril 2018.

OCAMPO, Juan. A. ¿Cómo fue el desempeño de América Latina durante la CRISIS FINANCIERA GLOBAL? Ensayos Económicos, N. 61/62, P. 7-33, 2011.

OCAMPO, Juan. A.; BASTIAN, Eduardo; REIS, Marcos. The myth of the 'Latin American deCAde'. PSL Quarterly Review, v. 71, N. 285, P. 231-251, 2018.

OSTRY, Jonathan; lOUNGANI, Prakash; FURCERI, Davide. Neoliberalism: Oversold? Finance \& Development, v. 53, n. 2, p. 38-41, 2016.

RAMOS, LeONARDO Y OtRos. A GoVERnANÇA ECONÔMICA GLOBAL E OS DESAFIOS DO G-20 PÓS-CRISE FINANCEIRA: ANÁLISE DAS POSIÇÕES DE ESTADOS UNIDOS, China, Alemanha e Brasil. Revista Brasileira de Política Internacional, v. 55, N. 2, P. 10-27, 2012.

REINHART, Carmen; TReBesCH, Christoph. The International Monetary Fund: 70 years of reinvention. Journal of Economic Perspectives, v. 30, N. 1, P. 3-28, 2016.

RIGGIROZZI, Pía; TUSSIE, DianA. RethinkING OUR REGION IN A POST-HegeMONIC MOMENT. IN: BRICEÑO-RUIZ JosÉ; MORALES, ISIDRO (Ed). PostHegemonic Regionalism in the Americas. Toward a Pacific-Atlantic Divide?. London: RoutLedGe, 2017.

STANLEY, LeONARdo; FERNANDEZ ALONSO, José. The ChANGING PROBLEM of Regional deVelopment finance in Latin America, In: VIVARES, ERnesto (Ed.). Regionalism, development and the post-commodities boom in South America. Hampshire: Palgrave, 2016.

SWiston, Andrew. Spillovers to Central America in light of the CRisis: What a difference a Year makes. IMF Working Paper, n. 10/35, 2010. The Glaner. Nigel Clarke In the Post-IMF World. The Gleaner, 9 MAY. 2018. DISPONIBLE EN: HTTP://JAMAICA-GLEANER.COM/ARTICLE/COMMEN- 
Prestamista, garante y deudor. El FMI en América Latina y el Caribe...

Pablo Nemiña ·Juan Larralde

TARY/20180509/EDITORIAL-NIGEL-CLARKE-POST-IMF-WORLD. CONSULTADO EL: 9 MAYO 2018.

UGARTECHE Oscar. Historia crítica del FMI. El gendarme de las finanzas. Buenos Aires: Capital Intelectual, 2016.

VADELL, Javier. La Red de Bancos de Desarrollo de China (RBDC) y sus implicaciones para América latina. Voces en el Fénix, N. 56, P. 22-29, 2016.

VERnENGO, Matías; FORD, Kirsten. Everything must change so that THE IMF CAN REMAIN THE SAME: THE WORLD ECONOMIC OUTLOOK AND THE GLOBAL financial stability report. Development and Change, v. 45, N. 5, p. 11931204, 2014.

WADE, Robert. EMERGING WORLD ORDER? FROM MULTIPOLARITY TO MULTILATERalism in the G20, the World Bank, and the IMF. Politics \& Society, v. 39, N. 3, P. 347-378, 2011.

WANG, Hongying. NeW multilateral DeVelopment banks: opportunities and Challenges for Global governance. Global Policy, v. 8, n. 1, P. 113-118, 2017.

WOODS, Ngaire. The globalizers. The IMF, the World Bank and their BORROWERs. ItHACA AND LONDON: CORNELL UnIVERSITY Press, 2006. 